\title{
An Analysis of Corporate Bonds Issuances in Malaysia
}

\author{
Noriza Mohd Saad ${ }^{1}$, Mohd Nizal Haniff ${ }^{2}$ and Norli Ali ${ }^{3}$ \\ ${ }^{1}$ Department of Finance \& Economics, Universiti Tenaga Nasional, 26700 Muadzam Shah, \\ Pahang, Malaysia, \\ ${ }^{2,3}$ F Faculty of Accountancy, Universiti Teknologi Mara, 42300 Puncak Alam, Selangor, \\ Malaysia.
}

\begin{abstract}
The objective of this study is to reveal an evocative statistical result on the bonds issuances for both, conventional bonds and Islamic bonds in Malaysia. Secondary data are obtained from Bondinfo hub, central bank of Malaysia on long-term and medium-term issuances of corporate bonds. There is 256 and 405 number of observations for long-term and medium-term issuances respectively. The independent samples T-test and Levene's test are utilized for hypotheses testing. Results revealed that conventional bonds yields have larger spread compared to sukuk in long-term issuances. However in medium-term issuances, the spreading of risk is larger in sukuk compared to conventional bonds. To the issuer, sukuk issuances is the best option in long-term capital financing otherwise conventional bonds issuances is better for medium-term period since their commitment to pay contractual interest is low.
\end{abstract}

Key words: Corporate Bonds, Sukuk, Issuance, Yield Spreads, Malaysia

\section{INTRODUCTION}

Bond issue by issuer have different yield to maturitiy that can be clustered into two main categories in capital market, namely medium-term and long-term issuances. Either conventional or Islamic bonds (hereafter refers as sukuk) both issuances belong to this cluster period. Yields of sukuk and conventional bonds represent the similar meaning that is return or investment profit to bondholders and cost of capital to the issuers. Bonds are a proof of debt includes a fixed rate of interest regardless of return either profit or loss, while sukuk are a proof of ownership related to the original legal contract that governs the relationship between the sukuk issuer and sukukholders. In addition to that, bonds expire at their pre-agreed value, whereas sukuk expire at either their market value, a prearranged figure which is agreed upon by the two parties or at a fair value.

In practice, sukuk investment actually does not show marked different to conventional bonds with regards to their yields. Computation of sukuk yields are the replicate of conventional bonds method or approach. It just a mimic of conventional bonds whereby sukuk features are replicating and mimic of conventional bonds [1], identical and always has time to maturity, a coupon rate, and trades on the normal yield price relationships and similar or same features [2-3] in their late payment penalty upon default, trading of debt based sukuk, purchase undertaking in equity based structures and ownership status in asset based transactions [1]. Sukuk shares some features with, and therefore often resembles, conventional bonds. But sukuk has a different underlying structure and provision compared to conventional bonds since it follows the shariah principles [4].

The specific techniques and methods to make it different was increasing interest among market players towards sukuk actually needed for establishing appropriate measure in recognizing and measuring transactions relating to the issuance and investment to ensure the trading compliant with shariah law [5]. Sukuk model is effectively a deviation of conventional securitization process where a special purpose vehicle acquire control of the originator's real assets and issues financial claims on the associated cash flows [6].

Though, yield spreads of sukuk actually less risky compared to conventional bonds [7] represented by little variation changes in macroeconomic risks [8] . However, instead of yield spreads as a proxy to measure the default risk, Fathurahman and Fitriati [9] used yield to maturity indicate that yield of sukuk greater than the average returns on conventional bonds as measured by standard deviation for the sukuk is relatively larger than the standard deviation of conventional bonds. Other proxy by using index from Bond pricing 


\section{Noriza Mohd Saad / International Journal of Business and Management, 2 (2) 2018, Pages: 11-16}

agency Malaysia (BPAM) in 2007-2012 studied on correlations of portfolio return [10], found that a significant and positive correlation between returns of sukuk and bond portfolios. Besides, revealed sukuk index outperformed the bond index and market index. Suggesting that, conventional bonds and sukuk has shared similar features and sukuk reports performed better.

\section{LITERATURE REVIEWS}

The development of a bond market was viewed as a priority because it served as an alternative source for raising capital [11-12]. However, the development of corporate bond markets should be viewed as a gradually incremental matter rather than rapidly implements process [11] for depending on banking institutions financing especially in huge amount.

Returning to the early history of the capital market in Malaysia, especially the beginnings of the bond market, one could trace it to pre-independence 1957. SC as the only regulatory body that provided regulatory oversight to the parties involved developed only in the 1990s. Prior to that, the task was left to the stock exchange and to some extent the Finance Ministry. Capital market development in Malaysia started in 1960 with the trading in Kuala Lumpur of the dual listed stocks and bonds in Singapore, which served as a market for what later, become two countries [13]. The real impetus came only when the Ringgit was adopted in June 1973 as the Malaysian currency and Kuala Lumpur traded the shares in the local currency. Due to the banking system having already been relatively welldeveloped, it provided much of the funding for domestic economic activity. In addition to the conventional banking system, Islamic banking also correspondingly offers the funding via sukuk certificates starting some 20 years ago.

The Islamic Banking Act of 1983 was based on an acknowledgement of the aspirations of Muslims to have non-usurious or riba-free banking and investment services as well as the government's goal of establishing a modern financial system in every aspect of Malaysia's socio-economic goals for the 21 st century economy. Even though the banking sector dominates the funding, there is a slow drift to use exchange sources for financing by firms and government.

Among the lingering effects of East Asian financial crisis in 1997, many public listed companies faced escalating difficulties as the plunge in share prices increased investor risk aversion and tight credit conditions severely affected financing lines at a time when liquidity was most urgently needed. The maturity mismatch was identified as a major source of systematic risk, but then, Capital Market Masterplan (CMP1) came out with a total of 152 recommendations including the establishment of Malaysia as an international Islamic capital market centre. This has reduced concentration and maturity mismatch risks as well as provides greater avenues for the financing of large-scale projects [14].

Considering this scenario, SC introduced Policies and Guidelines on Issue/Offer of Securities (Issues Guidelines) in July 1998 for additional capital-raising flexibilities. Further action was taken place with the formation of the National Economic Recovery Plan (NERP) in 1998 that highlighted the need for a broad, deep and well-developed bond market that would provide a more stable source of financing which would also diversify the risks associated with cyclical economic bearish. To recover the economic crisis, Malaysia needs to have developed an environment where capital can be mobilised to finance long-term investment and to provide a better match between risks and returns [12].

\section{METHODOLOGY}

There are 140 issuers with 407 tranche of issuances for long-term debt instrument consist of both, conventional bonds and sukuk obtained from bondinfo hub, Central Bank of Malaysia. Otherwise, there are 160 issuers with 610 tranche of issuances for both medium-term debt instruments. Initially, the period cover for both categories of debts, long-term and medium-term is from 2000 until 2014 respectively. Final data utilized in this study is 86 issuer firms with 112 tranches for LTCB and 54 issuer firms with 144 tranches for LTS. Therefore, a total sample for the long term debt instruments is 140 issuer firms with 256 tranches which cover a period of 2000 until 2014. However, sample from medium-term debt instruments indicate higher than long-term debt instruments. There are 160 issuer firms in total with 405 tranches but cover from year 2003 until 2014 since data on YTM from 2000 up to 2002 unavailable for medium-term debt instruments. There are two groups of study regarding to debt instrument has been categorized that is between conventional bonds and sukuk. This group then was clustered into long-term and medium-term instruments. They are needed to segregate into two different groups since their features and determinants might be different since the sukuk trading should straightly follows Islamic principles in their transaction event though they are trading under the same roof with conventional bonds. To test the significant mean different between these debt instruments therefore independent samples $\mathrm{T}$ tests and Levene's test are utilized.

The independent samples t-test evaluates the different between the means of two independent or unrelated groups. The t-value evaluates whether the mean value of the test variable from one group differs significantly from the mean value of the test 
variable for the second group. With respect to the comparing in number of observations for first and second group, it can be considered equal if the larger group is not more than 1.5 times larger than smaller group [15]. However, it is important to test the assumption of homogeneity of variance by Levene's Test [16] before testing for their independent sample T-tests, where the null hypothesis assumes no difference between the two group's variances as follows:

$H_{0}: \sigma_{1}^{2}=\sigma_{2}^{2}$

Where;

$\sigma_{1}^{2}=$ is the variance for the long term and medium term conventional bonds, and

$\sigma_{2}^{2}=$ is the variance for the long term and medium term sukuk.

If the F-value for the Levene's result is not significant, the assumption is met or not violated. Means, the equal variances assumed result is appropriate to be used. However, in the case that Fvalue is significant, the equal variances not assumed would be appropriate to be used [17] . This significance level is considered for three levels of $\mathrm{p}$ value at less than; 90 percent, 95 percent and 99 percent confident level. Notably that, with the significant result of F-value, the null hypothesis should be retained and concluded that there is no significant difference between the two group's variance which lead to further analyze on the result of independent sample t-test at equal variances not assumed column.

The null hypothesis for the independent sample T-tests is as follows:

$H_{0}: \eta_{1}=\eta_{2}$

Where;

$\eta_{1}=$ is the mean for the long term and medium term conventional bonds (first group), and

$\eta_{2}=$ is the mean for the long term and medium term sukuk (second group).

The significant t-value is based on value of alpha whereby p-value is less than 90 percent, 95 percent or 99 percent is satisfactory to justify the acceptance or rejection of the hypotheses developed. Rejection of the null hypothesis postulate that there are significant mean different between groups. Other than that, positive t-value denotes that the first group indicates higher mean than second group, otherwise negative t-value denotes that the second group indicate higher mean than first group.

\section{RESULT ANALYSES AND DISCUSSIONS}

Figure 1 and Table 1, 2 and 3 are show an evacotive statistics results of conventional bonds and sukuk yield spreads performance for all 6 clustered periods. For the first period is long term for conventional bonds and sukuk (LTCBS) which cover a year period of 2000 until 2014. Second period is medium term conventional bonds and sukuk (MTCBS) which cover a year period of 2003 until 2014. Both, LTCBS and MTCBS are represent a full sample of the study. Third and four periods are split from long term period into different instrument for long term conventional bonds (LTB) and long term sukuk (LTS) respectively. Otherwise, five and six periods are proxies by medium term conventional bonds (MTCB) and medium term sukuk (MTS) respectively.

The graph is important to highlight the minimum and maximum level of yield spread in order to know general performance of yields in Malaysia with respect to the cost of debt bearing by firms in bonds issuances. Minimum yield spreads for LTCBS, MTCBS, LTS and MTS show a negative value. Indicate that yield or cost of debt issued by the firms is below than the value of Malaysian treasury bills in that particular year. Undervalue offers attract bondholder or sukukholder to invest in the firm. Besides, it might be a factor of economic crisis in Malaysia for year 2008 that the issuers have to issue their debt at lower cost to the public and potential institutional investors.

The minimum value trend demonstrates a quite similar pattern to the mean value. Meaning that all the issuances tranche have competitive rate of yield offers during the contract initiated. However, only MTCBS, LTB, MTCB and MTS show a similar pattern for maximum value. But, the LTCBS and LTS obviously show a different pattern indicate a very high cost showed by value of yield spreads from long term sukuk issuances at 18.06 percent. Notably, this yield is different value of maximum and minimum of YTM which indicate the range of yield spreads is large up to maturity or tenure of issuances to be expired during the trading periods. The finding is consistent with the theory of Term Structure of Interest Rate whereby longer periods will have higher interest rate hence wider range of spreads associate to have higher default risks. Both instruments, either sukuk or conventional bonds were trading under the same roof, in the secondary market and through over the counter in Malaysia. Theoretically and conceptually, the main different is relying on sukuk trading shall be halal [18-19] in transactions and fully compliant to shariah Islam [20-21] but for conventional bonds is not restricted to this constituent. Sukuk offers unique benefits to corporate issuers unlike those of the conventional bonds through trade off and pecking order theory tested on firm's target debt optimizing behavior 
Noriza Mohd Saad / International Journal of Business and Management, 2 (2) 2018, Pages: 11-16

[22]. Empirically, the mean different can been seen from the results reported in Table 2.

It can be seen that yield spreads of LTCB (mean $=2.437)$ reported higher mean as compared to LTS (mean $=1.946$ ) with mean different at variance of 0.491 . Thus, indicate the sukuk yield spreads was performed better because a wider range of spread by conventional bonds given a huge chance for default risks to occur. Instead of analyzing on mean descriptive statistics result, Table 2 also scrutinizing for analysis of significant mean different based on independent t-test and Levene's test results. Both tests are important for the acceptance or rejection of the hypotheses developed in order to justify is there any differences between conventional bonds and sukuk yield spreads and its determinants.

With respect to yield spreads, F-value of Levene's test is 8.900 shows the result is significant mean different between LTCB and LTS at 95 percent confident level. This result associated with the equal variances not assumed considering the Levene's test result by adjustment for the standard error of the estimation [23] and by adjustment for the degrees of freedom [24]. Thus, hypothesis for the assumption of homogeneity of variance is met and failed to reject that there is significant mean different between yield spreads of LTCB and LTS. This result is justified by the independent t-test with positive tvalue of 2.384 at 95 percent confidence level.

The positive coefficient of estimation for $\mathrm{t}-$ statistics indicates that the yield spreads of LTCB was higher means than LTS issuances. It shows that, the wider range of yield spreads representing by higher means of long term conventional bonds indicate the level of default risks is higher compare to trading in long term sukuk. As what was claimed by empirical studies [2, 10, 25] that sukuk is just a mirror of bonds with respect to their yield spread or returns. However, the result of yield spreads finding is consistent with the study done by Mosaid and Boutti [10] whereby they found that a significant and positive correlation between returns of sukuk and bond portfolios. However, Safari, Ariff and Mohamed [2] argued that a new type of debt securities called sukuk certificates have grown to US\$ 840 billion in 11 financial markets as of 2011 . These Islamic debt instruments share some features similar to conventional bonds, so market operators treat both as bonds. Whether it is appropriate to treat sukuk certificates as conventional bonds is empirically tested in this paper. If the yields of sukuk are the same as those of conventional bonds,
Granger causality tests could confirm their equivalence. Practically the tests show otherwise. Also, the yields of sukuk instruments are significantly higher than yields of conventional bonds even after controlling issuers, rating quality and tenure in matched samples tests. They mentioned that sukuk issuance affects the issuing firm's beta risk significantly, which is consistent with capital structure theory. Their findings concluded that sukuk instruments should be classed as a new class of financial instruments, and not as bonds.

In conclusion, there are still mixed result reveal by many studies with respect to yield spreads in conventional bonds and sukuk. However based on this result, it shows that there is statistically significant mean different between yield spreads in LTCB and LTS issuances even though not too far (at variance of almost 0.5 only). Furthermore, higher spreads goes to LTCB not LTS since some discussion argument as above mentioned indicate sukuk have higher spreading in yields. Indicating that, LTCB will have higher default risk as compared to LTS.

Scrutinising Table 3, yield spreads of MTCB reported have lower mean (1.428) as compare to MTS (1.692). Meaning that, this medium term issuances is a good choice of investment due to bearing lower default risk as compare to long term issuances. Signify that, this result is contradicted with the yield spreads discussion in long term issuances. With respect to investigate the significant mean different of this variable, yield spreads for medium term sukuk and conventional bonds is significantly mean different demonstrate by F-value of Levene's test is 2.759 at 90 percent confident level. Thus, the hypothesis for the assumption of homogeneity of variance towards yield spreads is met and was fail to reject signify that there are significant mean different of yield spreads in MTCB and MTS. In addition to that, the results of t-test show a negative coefficient of estimations with a tvalue of -2.955 and it has significant at 95 percent confidence level. Indicating that, yield spreads of MTS has higher means compare than MTCBs' yield spreads. The wider range of yield spreads representing by higher means of medium term sukuk indicate the level of default risks is higher compare to trading in medium term conventional bonds. 


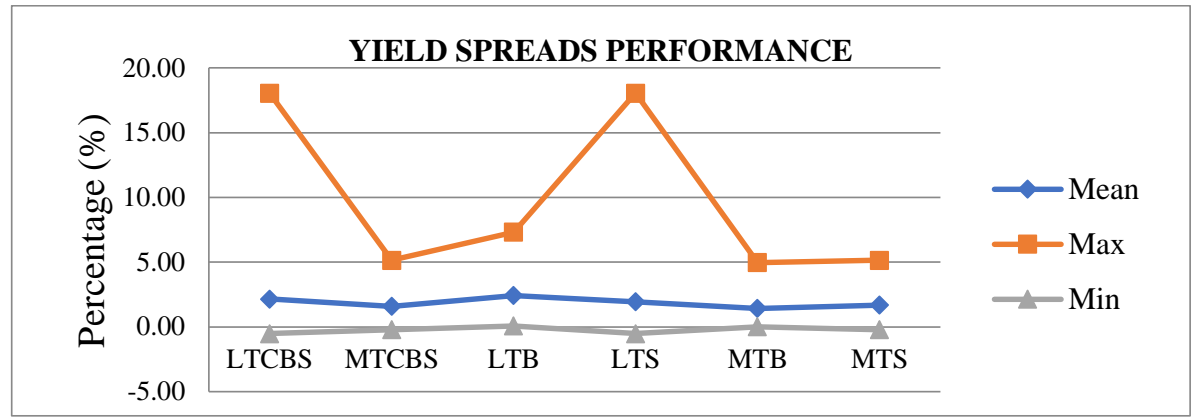

Figure 1: Performance of Yield Spreads according to Cluster Periods

Table 1: The Results of Mean, Maximum and Minimum of Yield Spreads according to Cluster Periods

\begin{tabular}{lllllll}
\hline Yield Spread & LTCBS & MTCBS & LTB & LTS & MTCB & MTS \\
\hline Mean & 2.16 & 1.59 & 2.44 & 1.95 & 1.43 & 1.69 \\
Max & 18.06 & 5.16 & 7.33 & 18.06 & 4.98 & 5.16 \\
Min & -0.52 & -0.20 & 0.08 & -0.52 & 0.02 & -0.20 \\
\hline
\end{tabular}

Table 2: A Mean Comparison of Variables between LTCB and LTS

\begin{tabular}{llllllll}
\hline \multirow{2}{*}{ Variables } & Mean & & t-test & & $\begin{array}{l}\text { Mean } \\
\text { Difference }\end{array}$ & Levene Test \\
& LTCB & LTS & $\boldsymbol{t}$ & $\boldsymbol{p}$ & & $\boldsymbol{F}$ & $\boldsymbol{p}$ \\
\hline Yspreads & 2.437 & 1.946 & 2.384 & .018 & .491 & 8.900 & .003 \\
\hline
\end{tabular}

Table 3: A Mean Comparison of Variables between MTCB and MTS

\begin{tabular}{llllllll}
\hline \multirow{2}{*}{ Variables } & Mean & & t-test & & $\begin{array}{l}\text { Mean } \\
\text { Difference }\end{array}$ & Levene Test \\
\cline { 2 - 9 } & MTCB & MTS & $\boldsymbol{t}$ & $\boldsymbol{p}$ & & $\boldsymbol{F}$ & $\boldsymbol{p}$ \\
\hline Yspreads & 1.428 & 1.692 & -2.955 & .003 & -.264 & 2.759 & .098 \\
\hline
\end{tabular}

\section{CONCLUSIONS}

This study contrasts two types of debt instrument, conventional bonds and sukuk by utilizing the independent sample T-test and Levene's Test methods. This contrast element mainly on their yield spreads as an indicator to default risk. The result indicates different effects between long-term and medium-term issuances of yield spreads. For instances, long-term conventional bonds yields have larger spread compared to long-term sukuk issuances. The segregation of the data into specific clustered panel based on period is important since most of the issuances are based on medium-term than long-term period. More importantly, this study reveals contradicted finding from the long-term issuances whereby medium-term sukuk yields have larger spread than medium-term conventional bonds issuances. Remarkably that, default risks is lesser to that issuer who issue long-term sukuk and mediumterm conventional bonds. On the contrary, default risk is higher among issuer who was issue long-term conventional bonds and medium-term sukuk. Long term sukuk is better investment than long term conventional bonds since its yield spreads is low and less volatile due to prohibited element of gharar (uncertainty) in their trading mechanisms. Issuer bear cost of sukuk lower than cost of conventional bonds in long-term issuances however inverse relation in medium-term issuances.

\section{REFERENCES}

[1] Lahsasna, A. \& Lin, L.S. (2012). Issues in Islamic Capital Markets: Islamic Bond/ Sukuk. 3rd International Conference on Business and Economic Research (3rd ICBER 2012) Proceeding. p. 495-512.

[2] Safari, M., Ariff, M. \& Mohamed, S. (2013) Do Debt Markets Price Șukūk and Conventional Bonds Differently?. Journal of King Abdul Aziz 
Noriza Mohd Saad / International Journal of Business and Management, 2 (2) 2018, Pages: 11-16

University (JKAU): Islamic Economies 26(2), 113-149

[3] Ariff, M. \& Safari, M. (2012). Are Sukuk Securities the Same as Conventional Bonds?. Afro Eurasian Studies, 1(1)(12), 101-125.

[4] Nanaeva, Z. \& Mammadov, R. (2010). Thoughts on Sukuk and the Risk of Default. Islamic Finance News 7(28), 14-15. https://www.scribd.com/doc/36450654

[5] Abd. Sukor, M.E., Muhamad, R. \& Gunawa, A.Y. (2008). Malaysian sukuk: Issues in Accounting Standard. Shariah Journal, 16(1), 63-74.

[6] Zaidi, J. A. (2007). Sukuk: A Global Trend. Chartered Financial Analyst Reference \# 01M2007-09-07-01, September 2007, p.35-39.

[7] Ramasamy, R., Munisamy, S. \& Mohd Helmi, M.H. (2011). Relative Risk of Islamic Sukuk Over Government and Conventional Bonds. Global Journal of Management and Business Research 11(6). Version 1.0 May 2011. Publisher: Global Journals Inc. (USA).

[8] Ellis, T.R. (2012). The Piety Premium of Islamic Bonds. Middle East Quarterly Spring 2012, 61-72.

[9] Fathurahman, H. \& Fitriati, R. (2013). Comparative Analysis of Return on Sukuk and Conventional Bonds. American Journal of Economics, 3(3), 159-163.

[10] Mosaid, F. \& Boutti, R. (2014). Sukuk and Bond Performance in Malaysia. International Journal of Economics and Finance, 6(2), 226234.

[11] Sharma, K. (2001). The underlying constraints on corporate bond market development in southeast Asia. World Development, 29(8). 1405-1419.

[12]Zakaria, Z., Hussin, Z., Noordin, N. \& Mohamed Sawal, M.Z. (2010). Financial crisis of 1997/1998 in Malaysia: causes, impacts and recovery plans. Voice of Academia, 5(1 ). 7996.

[13] Khalid, A. M. (2007). Bond Market Developments in Emerging Markets: Prospects and Challenges for Pakistan. SBP Research Bulletin, 3(1), 43-62.

[14] Capital Market Masterplan 2, Securities Commission of Malaysia. (2011). Available at: https://www.sc.com.my/wp-content/uploads/ eng/html/cmp2/cmp2_final.pdf

[15] Morgan, G. A., Leech, N. L., Gloeckner, G. W., \& Barrett, K.C. (2011). IBM SPSS for introductory statistics: Use and interpretation. (4th Edition). New York, NY: Routledge/Taylor and Francis.

[16] Levene, H. (1960). Robust testes for equality of variances. In Contributions to Probability and Statistics (I. Olkin, Edition), p. 278-292. Available At: http://www.ams.org/mathscinetgetitem?mr=0120709.

[17] Tabachnick, B.G. \& Fidell, L.S. (2007). Using Multivariate Statistics (5th Edition). Needham Heights, MA: Allyn \& Bacon.

[18]Box, T. \& Asaria, M. (2005). Islamic finance market turns to securitization. International Finance Law Review 7, 22.

[19] Jobst, A., Kunzel, P., Mills, P. \& Sy, A. (2008). Islamic Bond Issuance - What Sovereign Debt Managers Need to Know. Unpublished. Available at: http://www.imf.org/external/pubs/ft/pdp/2008/ pdp03.pdf

[20] Saeed, A. \& Salah, O. (2014). Development of Sukuk: Pragmatic and Idealist Approaches to Sukuk Structures. Journal of International Banking Law and Regulation 1, 41-52.

[21] Taqi Usmani, M. (2007). Sukuk and their Contemporary Applications. (Translated from the original Arabic by Sheikh Yusuf Talal DeLorenzo), AAOIFI Shari'a Council Meeting, Saudi Arabia. Available at http://www.kantakji.com/media/7747/f148.pdf

[22] Mohamed, H. H., Masih, M., \& Bacha, O. I. (2015). Why Do Issuers issue Sukuk or Conventional Bond? Evidence from Malaysian Listed Firms Using Partial Adjustment Models. Pacific-Basin Finance Journal. doi:10.1016/j.pacfin.2015.02.004.

[23] Cochran, W.G., \& Cox, G.M. (1957). Experimental Designs. New York: John Wiley \& Sons.

[24] Satterthwaite, F.W. (1946). An Approximate Distribution of Estimates of Variance Components. Biometrics Bulletin 2, 110-114.

[25] Aboody, D., Hughes, J.S. \& Ozel, N.B. (2014). Corporate bond returns and the financial crisis, Journal of Banking \& Finance 40, 42-53. 